\title{
La paronomasia en la literatura árabe y española: Estudio Comparativo
}

\author{
Abdelaziz Fahd"
}

\section{Preliminar}

Podemos designar con el término "juego de palabras" unos fenómenos que están basados en una relación entre la asociación o la sustitución, y la derivación...etc., Estos fenómenos guardan una relación muy estrecha entre sí, como por ejemplo : homonimial, antanaclasis $^{2}$, calambur $^{3}$ y paronomasia. El juego de palabras se ocupa un lugar intermedio entre los juegos con letras, sílabas, rimas y géneros literarios. Se considera como un recurso artificial muy cultivado p or muchos autores, tanto en la literatura española como en la árabe.

Plett "sitúa el juego de palabras al nivel de las llamadas figuras morfológicas, que se caracterizan por la identidad o similaridad de dos o más morfemas en un texto con otros términos. El juego de palabras pertenece a la figura de repetición". Añade que éste ocupa un lugar particular y ambiguo en este grupo, dado que la repetición idéntica de una palabra puede ser modificada no solamente a través de desviaciones morfológicas sino también por procedimientos fonológicos, semánticos y grafémicos. Plett afirma, que "si se modifica uno o varios de estos aspectos, permanecen iguales los demás, entonces la equivalencia morfológica contiene un juego de palabras" ${ }^{4}$.

La definición del juego de palabras ha sido magníficamente expuesta por Kurt Spang. Algunas de sus i deas básicas me tomo la libertad de reproducir aquí:

\footnotetext{
Facultad de Al-Alsun. Universidad de Minia.
} 
1. El juego de lengua se basa en una manipulación de la lengua que en sí no se diferencia de manipulaciónes no lúdicas. El hecho de que sea lúdico se advierte a través de una contradeterminación
contextual, situacional o grafémica.

2. Esta contradeterminación nos revela una actitud "como sí"; es decir, el hablante actúa como si su empleo del lenguaje fuese no lúdico y en realidad la manipula premeditadamente. La percepción del juego es, por tanto siempre a posteriori, por lo menos no se produce antes de que el receptor no se haya dado cuenta de la señal contextual,
situacional o grafémica.

3. La repetición de un grupo de dos palabras levemente, modificadas, nos sirve de señal contextual para destacar el juego. Aquí, como en otras ocasiones, sería esquizofrénico separar totalmente significante y significado, puesto que contribuye también a la señalización del juego el cambio semántico producido por la alternancia "yo"- "ya" y la alusión al fenómeno gramatical de que "-0" es por lo general terminación masculina y "-a" femenina.

4. Los juegos de lengua se producen en todos los niveles del lenguaje. Se puede jugar con la puntuación, la acentuación, con las letras, el
morfema, el sintagma y el texto.

5. Un juego de lengua no tiene que ser forzosamente cómico o gracioso, aunque lo es con frecuencia.

6. Los juegos de lengua no constituyen un recurso exclusivamente literario; son posibles a todos los niveles y en todos los empleos del idioma desde el lenguaje infantil y pasando por modismos, refranes y chistes hasta la creación literaria.

7. Aquí, como en otros recursos lingüístico-retóricos, cabe distinguir entre juegos de lengua originales e innovadores y juegos
habitualizados o lexicalizados.

8. El juego de lengua no es un género literario, sino un procedimiento de manipulación del lenguaje. Ocurre que ciertos géneros están intrínsecamente vinculados con el juego de lengua (por ejemplo, la
charlada, el anagrama, el acróstico, el lipograma, etc.)

Bice considera "juego de palabras" como una subclase de figuras de repetición, se caracteriza por las diferencias entre los miembros, diferencias provocadas por la variación de la forma y la función sintáctica de las palabras o por el uso de las mismas con sentidos distintos en un mismo contexto. Bajo el juego de palabras abarcarán la envoltura verbal (paronomasia), se aprovechan las variaciones 
funcionales de la flexión (poliptoton), o la identidad de la raíces (figura etimológica) ${ }^{6}$.

José Antonio Mayoral explica :"tales fenómenos vienen a ser resultado de muy particulares $\mathrm{c}$ insperadas manipulaciones, ejercidas de forma consciente y delibrada sobre los componentes significantes $y$ significados de las unidades lingǘsticas, $y$ en las que se hacen intervenir fundamentalmente, peculiares fenómenos de asociación y/o sustitución entre unidades léxicas homonimicas (homofónicas y homográficas), paronímicas, polsémicas, sinonímicas, antonímicas, etc., en determinadas segmentos del discurso"?

\section{La definición de la paronomasia}

Como explica Mario García-Page ${ }^{8}$ se entiende comúnmente por la paronomasia el juego lingüístico que se constituye al poner en relación dos o más palabras fónicamente semejantes. Pero, J.A. Mayoral da una definición .más amplia respecto a esta figura "palabras cuyos significantes (fónicos $y / 0$ gráficos) son parcialmente idénticos 0 guardan mayor o menor grado de semejanza que no comparta una correspondencia en el plano de los significados"'.

Los tratadistas españoles del Siglo de Oro han definido la paronomasia en palabras parecidas. La figura en cuestión para Gonzalo Correas "es asonada semejanza en el sonido de la palabra, cuando se trueca una dicción, nombre o verbo, mudando alguna letra, en otra palabra de contraria o muy diversa significación, por gracia por encarnecer" ${ }^{10}$. Fernando de Herrera ha s eñalado a la paronomasia en dos lugares distintos, el primero "paronomasia del nombre al verbo, respiramos es de maravilla significación; porque es descansar del trabajo", y explica en el segundo, "paronomasia o anominación, o alusión de sílabas"."

Respecto a esta figura el gramático Antonio Nebrija dice lo siguiente "paronomasia es cuando un nombre se hace de otro en diversas significaciones, cuando diciendo, no es orador, sino arador; llama paronomasia y quiere decir denominación". En la opinión del 
retórico Sínchez de las Brozas "paronomasia o nominación es el cambio hacia una palabra semejante", 12

Vale la pena decir que la paronomasia es un sistema común relacionado con las raices de las palabras, pero muy parecidas en el plano de la expresión. Al mismo tiempo, se puede considerar como un tipo de imitación fónica, la cual se produce a través de repetir unas letras o unas silabas. En todos los modos, el significante permanece intacto pero cambia el significado, esto, permite comprobar monológicamente en la diáfora o dialógicamente en la antanclasis, en que puede observarse las diferencias de significado que puede suscitar una repetición, en todo caso, se unen ingeniosamente formas distintas de la misma palabra, homónimos y formas polisémicas.

Después de haber expuesto muchas definiciones y descripciones de varios retóricos y gramáticos pertenecientes tanto a los del Siglo de Oro como a los contempráneos, cabe decir que la figura en cuestión, es una reunión de dos o más palabras cuyos significantes son parecidos, por semejanza causal respecto a lo fónico y/o lo gráfico, o bien, parentesco etimológico. Pero este fenómeno ha venido siendo descrito en la tradición gramatical y retórica bajo denominaciones como paronomasia, anominación o nominación. ${ }^{13}$

Respecto a los autores árabes definen, la paronomasia o. (elGuenas) en términos parecidos y estos ejemplos semejantes. De las definiciones recojo la de Abdel Kaher el-Guergany, quien se refiere a esta figura en los términos siguientes ${ }^{14}$

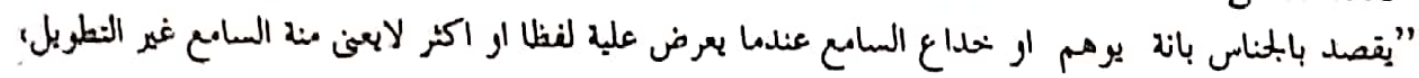

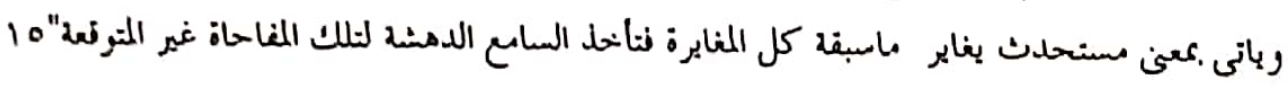

\section{Origen de la paronomasia (El-Guenas)}

En la época griega la palabra paronomasia se produce un cambio muy leve en; se nos revela un sentido diferente; cuando dos o más vocablos suenan de manera semejante, pero tienen distinta significación.

Respecto a este fenómeno Aristóteles dice: "lo que sucede cuando es inesperado, y, como aquél dice, diverso de la opinión que antes se 
tenía, como los que hacen parodias en las piezas cómicos, lo cual logran también los juegos, porque engafian. También en los versos; porque no es como esperaba el oycnte "caminaba llevando en los pies sabañones" mientras que uno esperaba que dijera no sabañones, sino sandalias. Mas preciso, una vez que haya sido dicho, que sea claro. El juego de palabras dice lo que no dice, sino lo claro que el nombre varía, por ejemplo, lo de Teodro contra Nicón el citaredo; "la tracia cantó" que parece quiere decir "te confunde: y engaña; pues dice cosa. Por lo cual es agradable para el que lo sabe, mas si no entiende que Nicón es tracio, no parecerá que es esto gracioso..."15

Durante la época latina la retórica, se fija solamente en los modos de constituir la figura (annominatio), entre las cuales señalaron:

1. Adición o sustracción de una letra \{sonido\} o sílabas, o mnibushominbus.

2. Conmutación (per inmutationem), nobilem/movilem.

3. Alargamiento o abreviación, ãvium-ãvium.

4. Permutación (per transmutationem), navo-vano.

Como explica J.Antonio Martínez García "lo que hoy se entiende por paronomasia, no difiere, en esencia, de la doctrina retórica: figura que consiste en aproximar palabras fónicamente similares (por parentesco etimológico o pura casualidad). Pero tales definiciones contemplan sólo casos extremos; desatiendo otros menos sensibles pero más abundantes. Entre los juegos, ni un solo texto "léxico": la paronomasia fue rama dialéctica, figura de oratoria; hoy se ejemplifica en refranes" ${ }^{16}$. Esto por un lado.

Y, por otro, encontramos gran grupo de los críticos árabes que consideran que la paronomasia es de origen árabe, como explica Ibrahem Salama, El-Guenas apareció en la poesía de el-Gahez, dejó muy claro que la figura en cuestión la insertó Iben el-Muhtaz entre las figuras de la dicción, (el-badya) y, se puede encontrar unas muestras más representativas de la paronomasia tanto en la literatura clásica como en la moderna ${ }^{17}$. 
Es digna de citar aquí la opinión de el-Guendy ${ }^{18}$ quien dice que la paronomasia es una figura idénticamente árabe. Sin embargo, no niega la influencia de Aristóteles sobre los árabes, y propone lo siguiente:

$$
\begin{aligned}
& \text { 1. الحناس من البلاغة الفطرية الى تسرى على الألسنة بلا كد. } 19
\end{aligned}
$$



$$
\begin{aligned}
& \text { r. مشفف العربىبالغناء والايقاع-الجناس شعبه من ذلك. }
\end{aligned}
$$

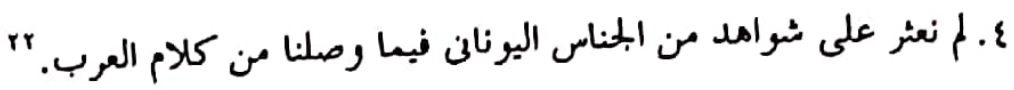



A mi juicio, creo que la paronomasia, es un fenómeno occidental que pasó de la retórica de Aristóteles a la literatura árabe a través de las traducciones de sus obras en la época abbasi. Al mismo tiempo, no debemos olvidar que los árabes hicieron gran esfuezo respecto a la clasificación de la figura en cuestión, porque las palabras de Aristóteles no indican una figura en especial, sino también otras, cabe citar entre ellas, metáfora, antanclasis, calambur paronomasia...etc.).

Huelga decir que el hecho de emplear normas o reglas literarias extranjeras en cierta literatura no perjudica a la literatura prestataria a condición de aportar nuevas ideas. Las comunidades más listas son las que saben aprovechar el patrimonio cultural del pasado, y eso es precisamente, lo que hicieron los árabes, al descubrir la retórica aristotélica.

\section{Clasificación de la paronomasia en árabe}

Las variedades que ofrecen la realización de esta figura han sido analizadas $\mathrm{y}$, clasificadas según dos criterios diferentes en la r etórica árabe: 


\section{A)Paronomasia completa}

Bajo la denominación de este tipo, podemos insertar dos palabras o más parecidas en cuatro categorías:

1. En las letras de cada palabra.

2. En el número de las letras.

3. En la forma de las letras.

4. En el orden de las letras.

A continuación citaré algunos ejemplos sacados de el-Corán y de la literatura árabe:

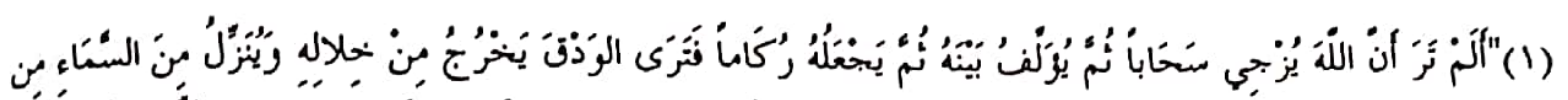

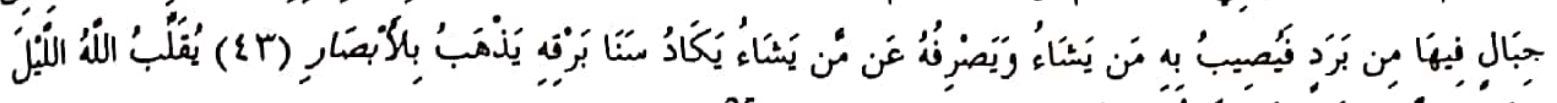

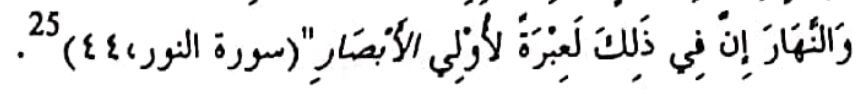

En este ejemplo, hay dos parónimos muy parecidos en cuatro categorías; en las letras, en su número, en su forma y en su ordenación, pero cada uno de ellos tiene significado distintọ, el primero es, الأبصـارsignifica "la vista" y el segundo es, الأبصار significa "las evidencias".

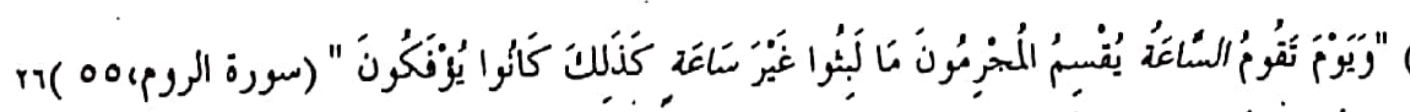

Se puede observar en este éjemplo dos parónimos, el primero es, السباءignifica "el último día", el segundo es, ساعignifica "una hora".

$$
27 \text { فلا يضرب بالبيداء فلا يضل ويضرب فن المجاءُفلا يكل }
$$

Se puede ver en el citado ejemplo los dos parónimos muy parecidos en el significante, a la vez, pertenecen a la misma categoría gramatical, (verbo + verbo) el primero es, يضرب significa "cortar distancia", mientras que el segundo parónimo يضرب significa "lleva contra los enemigos".

$$
28 \text { (ع) مات من كرم فإنه يحيا لدى يكي بن عبد الله }
$$


En este ejemplo observamos que cada uno de los dos parónimos pertenece a una distinta categoría, el perimero, es un verbo يكيـ significa "vivir", el segundo, ئ es un "nombre propio".

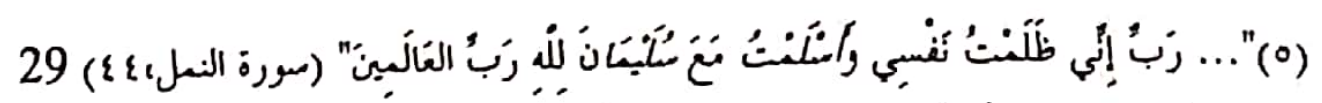

Podemos observar en este ejemplo, que los parónimos pertenecen a dos categorías distintas, uno, الملت significa "me someto", otro, سبكان un "nombre propio".

\section{B)Paronomasia incompleta}

Es cuando coinciden los dos parónimos, sólo en una de las cuatro categorías citadas anteriormente, la semejanza corresponde a las letras, al número de las letras, a la vocalización de las letras o al orden de las letras. He aquí unos ejemplos:

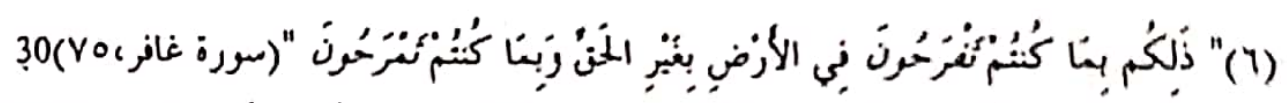

Observemos que los dos parónimos se diferencian sólo por una letra, significa "alegrarse" y, نفرحون significa "divertirse".

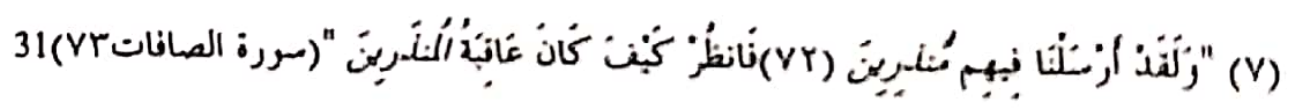

Se puede ver en este ejemplo que los parónimos cuentan con una vocalización diferente, el primero, مُنـــ significa "amonestadores", el segundo, المنذرين significa "amonestados".

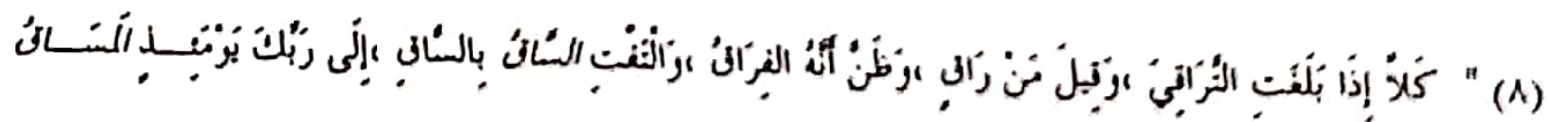

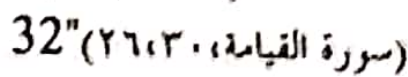

Vemos que en este ejemplo, la primera palabra السـان significa "la pierna", mientras que la segunda المساق significa "el camino".




Podemos ver en este ejemplo una permutación entre los dos parónimos, (se desacuerdan en el orden de las letras) el primero, بـ significa "entre" y el segundo, بنى significa "hijos de".

\section{Clasificación de la paronomasia en español}

Desde la antigüedad, la paronomasia procede de la ordenación de unos fenómenos. Es sabido que, aquéllos presentan diversidades en la realización, en función de las cuatro categorías modificativas. J iménez Patón ${ }^{34}$ se considera uno de los mejores tratadistas españoles del Siglo de Oro, que trató la ordenación con de los parónimos como aparece en los siguientes puntos:

1. Por adición: cubrir-descubrir, celoso-receloso.

2. Por supresión: palio-palo.

3. Por permutación: orador-arador, consumar-consumir.

4. Por inversión: roma amor, Isabel-Belisa.

Como señala M. García-Page la distinción, tiene que ser estudiada desde diversos puntos de vista, la primera distinción se basa en la praesentia o ausencia de los parónimos (paronomasis in praesential paronomasia in obsentia). Otra diferenciación que puede hacerse atiende al carácter continuo o discontinuo con que se presenta los sonidos recurrentes ${ }^{35}$. A continuación, me referiré a los siguientes tipos:

\section{A)In paresentia}

La definición retórica respecto a este término "al circunscribir a los límites de la palabra, es más restrictiva $\mathrm{y}$ desatiende fenómenos parnomásticos como los que siguen:

(1) Cómo después de acordado

Da dolor.

(J. Manrique)

(2)Ahora digo, ponderó Critilo, que con razón se llevamos corazón" ${ }^{36}$.

(B. Gracián) 


\section{a)paronomasia de inclusión e intersección}

En éste podemos ver que el significante de una de las palabras coincide con un segmento paronomástico. Veamos unos ejemplos:

(3) Ladró al ladrón

(Quevedo)

(4)"Y esto dijo en voz tan alta, que cayóla duquesa, volviendo y viendo a la dueña tan albortada y tan encarnizados los ojos, le preguntó con quién las había".

(M. de Cervantes) ${ }^{37}$

(5)Fuese la gente volvieronse el duque y dar Quijote al castello encerraron a Tosilos,quedaron doña Rodríguez y su hija contentísimas de ver que, por una vía por otra, aquel caso había de parar en casamiento, y Tosilos no esperaba menos". (M. de Cervantes) ${ }^{38}$

\section{b)paronomasia quiástica}

Se trata de unos fonemas que se repiten siguiendo un orden permutado o inverso, como explica Martínez García "se repite el segmento paronomástico respecto al otro u otros. Se forma una construcción simétrica o especular. Los segmentos permutados p ueden $s$ er fonemas (consonánticos; o vocales; o consonantes y vocales) y sílabas". ${ }^{39} \mathrm{He}$ aquí
unas muestras:

(6)Barco de Avila, torreón de alba.

(M. de Unamuno)

Avila

Al..ba

(7)...

mayorazgo del oriente

primogénita del día, tálamo al túmulo junto, 
en donde eres madre e hija...
(F. Quevedo, p. 825)

consonántica suele darse puede observar que la paronomasia quiásmica contextos de vocales que se reiteran.

(8)sus zapatos de charo!

Rompen las dalias del aire

(F. García Lorca)

Obsérvese cómo la paronomasia sólo se da en contextos consonánticos que se reiteran en un orden sucesivo.

\section{B) Paronomasia in absentia}

En este tipo encontraremos uno de los parónimos que se expresa de una forma indirecta, connotativamente; 0 en otras palabras, es evocado por el otro parónimo desde el plan de expresión, y, desde el de contenido, por otro u otros signos del texto. Veamos a continuación unos ejemplos:

(9)eș vuestro 'capón' sin vos

sacristía sin \{cojones\}

\{cajones\}

(F.Quevedo)

(10)que se pasee Narciso

con su cuello en 'paraíso'

bien puede ser;

mas que sea notario

$$
\{\text { purgatorio }\}
$$

que anda el cuerpo en [pulgatorio]

no puede ser

(Góngora) $^{41}$

En resumen, hemos podido comprobar a través de este brevísimo recorrido en la paronomasia (El-Guenas) que tanto en la literatura árabe como en la española, se puede apreciar tales fenómenos, ante todo y sobre todo la figura en cuestión, a bordar el tema, de las divergencias en cuanto a la clasificación y a la hora de analizar su funcionamiento dentro de la obra literaria. 
'Bste fenúmeno so produce cunudo varias palabras de distinto significado tienen igunl pronuncinción y graffa, o solamente igual pronunciación, y distinta significación.

'Seguin José Luis Gareln BARRIENTOS, (1998): Las figuras retóricas.Madrid, Arco/Libros, pp. 37-38, la antanaclasis, es una repetición de una misma palabra polisémica (o de palabras homónimas) con dos significados diferentes. He aqui un ejemplo: Cura gracioso y parlando/sus vecinas el doctor,/y siendo un gran hablador/ es un matalascallando./A su mula mata andando, /sentado mata al que cural a su cura sigue el cural con requiem y funeral/ Y no lo digo por mal (Quevedo).

3Véase Ana María PLATAS TASENDE, (2000): Diccionario de términos literarios. Madrid, Espasa, p..95. calambur es un juego de palabras cercano a la paronomasia. Se produce cuando las sílabas de una o más palabras, agrupadas en o tro modo, sugieron u n s entido distinto. Aunque aparece en otros géneros literarios, el que hace su uso más rentable es el teatro cómico, pues los efectos del calambur se acrecientan cuando se capta por vía oral...en el comienzo de La vida es sueño, obra no precisamente cómica, encontramos un famoso y discutido calambur: y apenas cuando llega a penas. (penas=dolores: apenas, adverbio = "en cuanto, "tan pronto como "...etc.

${ }^{4}$ Cf. H. F. PLETT, (1979): Textwissenschaft und text-analyse: Semiotik, Linguistike, Rhetorik. Heidelberg, Quelle und Meyer, p. 217, citado por Kurt SPANG, (1983): "semiología del juego de palabras" en Teoría semiótica Lenguaje y textos hispánicos vol, I, Madrid, pp.295-303, en concreto, pp. 296-297.

5 ibid.300-301.

6.Vid. Bice MORTARA GARAVELLI, (1991): Manual de retórica. Madrid, Cátedra, p.235.

7 , José Antonio MAYORAL (1994): Figuras retóricas. Madrid, Síntesis, pp. 116-117. 
Mario GARCÍA-PAGE, (1990): "Datos para la tipología de la paronomasia" en Epos, 8, pp. 155-243, especialmente p. 155-158.

9 Véase J.A. MAYORAL, (1994): Figuras...ed..cit., p.122. Véase también Pierre FONTANIER, (1968): Les figures du discours. Paris, Flammarion, p.347, , Victor GRIGORIEV, (1978): "L'attraction paronymique", en V. GRIGORIEV, (Ed.) (1981): Linguistique et poétique. Moscú, Editions du progres, pp.324-331, especiamente p.325, y Helena BERISTÁIN, (1985): Diccionario de retórica y poética. México, Porrúa, p.386.

${ }^{10}$ Gonzalo CORREAS, (ca 1626): Arte de la lengua española castellana. Madrid, Selecciones Gráficas, 1954, p. 413.

"Fernando de HERRERA (1580): Obras de Garcilaso de la Vega con Anotaciones de ..., en Gallego Morell, A. (ed.) (1972): Garcilaso de la Vega y sus comentaristas. Madrid, Gredos, p.516 y p.529.

${ }^{12}$ Antonio de NEBRIJA, (1492): Gramática de la lengua castellana. Madrid. Editora Nacional, 1981, p. 220 y F. SÁNCHEZ de las Brozas, (1579): Organum dialecticum en rhtoricum, en escritos retóricos. Cáceres, Institución Cultural El Brocence, 1984, pp.161-371, especialmente p.159.

${ }^{13}$ Heinrich LAUSBERG, (1960): Manual de retórica literaria. Madrid, Gredos,§§, 637-639.

${ }^{14} \mathrm{Se}$ cae bien al oído, porque cuando se repite una o más palabras semejantes, se engaña al oyente, y a la vez, nos sorprende el autor con un significado distinto. (traducción del autor)

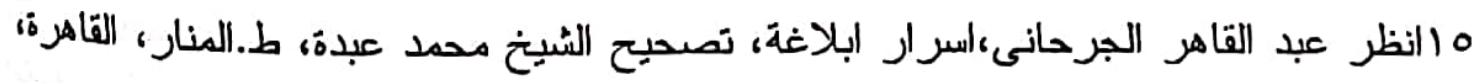

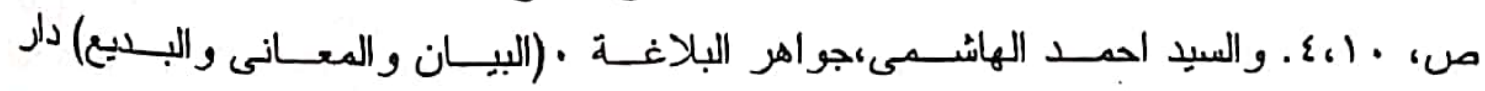
${ }^{16}$ ARISTÓTELES, (1971): Retórica. Ed. Antonio Tovar, Madrid, Instituto de Estudios Políticos, pp. 205-206.

${ }^{17}$ José Antonio MARTÍNEZ, (1976): "Repetición de sonidos y poesía", en Archivum, 26, pp.71-102, en concreto, pp. 73-74. 


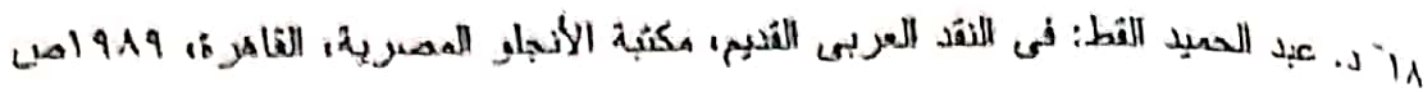
$.1 Y$. 10 Y

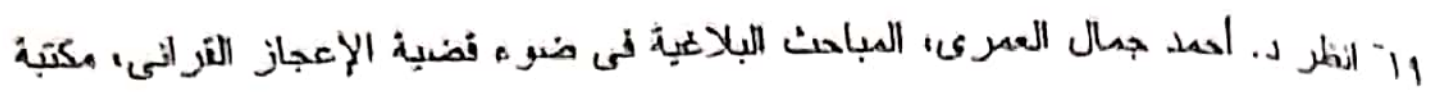

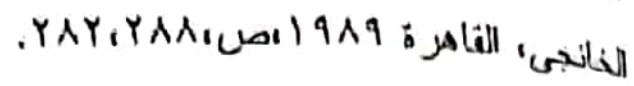

20 Se considera la paronomasia parte de la retórica inartificial que corre por las lenguas sin cansancio.(traducción del investigador).

21 La abundancia de los ejemplos en la literatura árabe tanto en la clásica como en la contemporánea.(traducción del investigador).

${ }^{22}$ La pasión de los árabes por la música y el ritmo, esto, se refleja en la paronomasia. (traducción del investigador).

${ }^{23}$ No hallamos muestras de paronomasia griega en el habla de los árabes. (traducción del investigador).

${ }^{24} \mathrm{La}$ definición de la paronomasia y sus clases está puesta por Iben ElMuhtaz. (traducción del investigador).

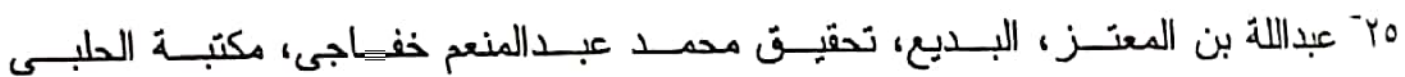
( )

26 , JUAN VERNET, (1983): El Corán. Barcelona, Planeta, p. 366. "¿No has visto que Dios impulsa las nubes, luego las reúne entre sí y luego las coloca en estratos? Entonces ves que la llovizna sale de sus entrañas. Él hace descender desde el cielo montañas de nubes en las que hay granizo; con él daña a quien quiere y lo aparta de quien quiere, mientras el resplandor del relámpago que lo acompaña casi arranca la vista. Dios transforma la noche y el día. En eso hay una lección de los evidentes".

27 Ibíd. pp.424-425. "el día en que se incorpore la Hora, los culpables jurarán que no han permanecido más que una hora en sus tumbas". 22 Fulano corta la distancia en el desierto sin perderse/ y pega (lleva contra) los enemigos sin cansancio. (tradución del investigador). 


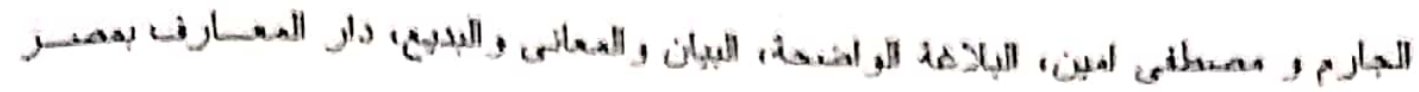
YTr.YTAR(una) 197

25 Nunca se muere la generosidad, mientras que viva Yahia ben Abdoulah, (traducción del investigador). hais pasal

29 J. VERNET, (1983): El Corán. ed. Cit., p.349, "se le dijo: "¡Entra en el palacio!" Cuando lo vio, creyó que era un estanque, y puso sus piernas al descubicrto. Salomón dijo: "Es un palacio cnlosado de cristal". Ella exclamó: "¡Señor mío! He s ido i njusta c onmigo. C on S alomón, yo me someto a Dios, Señor de los mundos".

${ }^{30}$ Ibid. p.498, "Esto os ocurre porque sin razón os alegrasteis en la tierra y porque os divertisteis en el pecado".

${ }^{31}$ Ibid. p. 469, " a pesar de que enviamos entre ellos amonestadores. ¡Obseva cuál fue el fin de los amonestados".

32 Ibid. p. 635, "i No! Cuando el alma alcance las clavículas y se le pregunte: "¿Quuién es el hechicero?". Pensará que es la separación. Y la piema entrechocará con la otra pierna . en ese día la marcha conducirá a tu Señor".

33

M.E Editores, (1995): El Corán. Barcelona, Ibérica Grafic, p.219, " ¡Oh hijo de mi madre! Respondió Arón, cesa de tirarme de la barba y de la cabeza.He temido que me dijeses en seguida: ¿Por qué has sembrado la escisión entre mi y los hijos de Israel".

${ }^{34}$ B. JIMÉNEZ PATÓN, (1604): Elocuencia española en arte. Madrid, El Crotalón, 1987, p. 115.

${ }^{35}$ M. GARCÍA-PAGE, (1992) "Datos..." en Epos, 8, ed. cit, pp. 155-243.
${ }^{36}$ Véase J.A.MARTÍNEZ, (1976): " Repetición..." en Archivum, 26, ed.
Cit., p.47. 37 Miguel de CERVANTES, (1994): Don Quijote de la Mancha II,
Madrid, Cátedra. P.260

38 Ibid. p. 450 

${ }^{39}$ MAR'TINEZ, J. A. (1976): "Repetición..." en Archivum, 26, op. Cil,
pp. 76-79.

40 Francisco de Quevedo, (1991): Poesía original completa, Barcelona, Planela, p.825.

"los ejemplos n. 1-3, 6, y 8-10, citados en Martínez, J.A. (1976): Archivum, op. Cit,. pp. 74-79. 


\section{1-En Espafiol:}

\section{Referencias Bibliográficas}

ARISTÓTELES, (1971): Retórica. Madrid, Instituto do Istudios l'ollticos. Barrientos, J.L.G. (1998): Las figuras retoricos. Madrid, Arco/Libros. BERISTÁIN, H. (1985): Diccionario de retórica y poética, México, Porrúa. CERVANTES, M. de (1994): Don Quijote de la Mancha II, Madrid, Cátedra. FONTANIER. P. (1968): Les figures du discours. Paris, Plammarion. GARCIA-Page, M. (1992): "Datos para una tipología de la paronomasia", cı Epos, 8. pp. 155-243.

GRIGORJEV, V. (1978): "L'attraction paronymique", cn cn Grigoricv, V.(Ed.) (1981) : Linguistique poétique. Moscú, Progrcso. HERRERA, F. de (1580): Obras de Garcilaso de la Vega con Anotaciones de ...en Gallego Morelle,A.(Ed)(1972):Garcilaso de la Vega y su comentaristas, Madrid, Gredos.

JIMÉNEZ PATÓN, B. (1604): Elocuncia española en arte. Madrid, El Crotalón, 1987.

LAUSBERG, H. (1960): Manual de retórica literaria, Madrid, Gredos, 3 vols. MAYORAL; J.A. (1994): Figuras retóricos. Madrid, Síntesis.

MARTÍNEZ, J.A.(1976): "Repetición de sonidos y poesía", en Archivum, 26. MORTARA GARAVALLI,B. (1988): Manual de retórica. Madrid, Cátedra. NEBRIJA,A. de (1492):Gramática de la lengua castellana. Madrid,Editora Nacional, 1981.

PLATAS TASENDE, A.M. (2000): Diccionario de términos literarios. Espasa. PLETT, H. F. (1975): Textwissenschaft und Textanalyse: Semiotik, Linguistik, Rhetorik. Heidellberg, Quelle und Meyer.

SÁNCHEZde las Brozas, F, (1579): Organum dialecticum et rhetoricum, en Escritos retóricos, Cáceres, Institución Cultural El Brocense, 1984.

SPANG, K. (1983):"Semiología del juego de palabras", en Teoria semiótica. Lenguaje y textos hispánicos.Madrid,

C.S.I.C.

VERNET, J. (1983): El Coráı. Barcelona, Planeta.

\section{2-En Árabe:}

عبدالقاهر البرحامن، امرار البلاغد، تصحيح الشيخ محمد عبده ، ط.المنار،القاهرة.

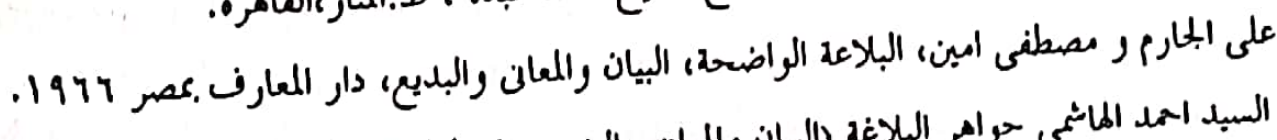

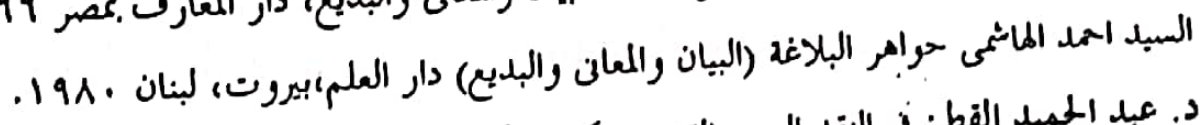

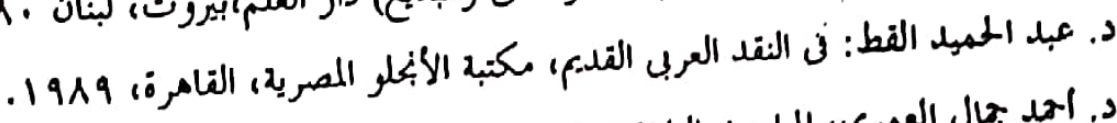

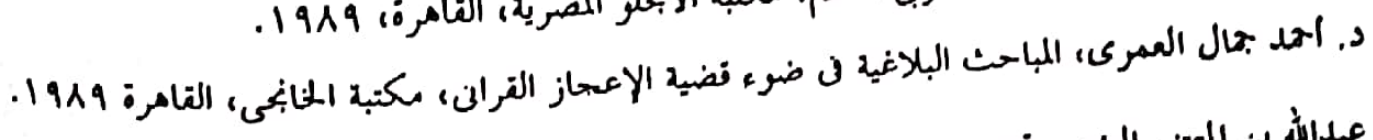

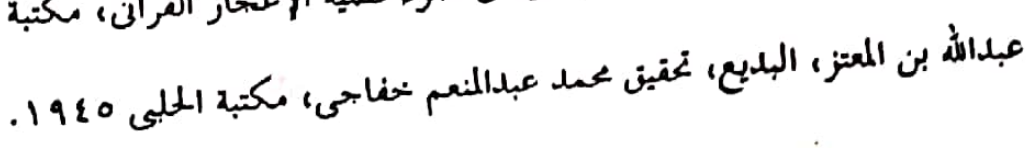




\section{Resumen}

\section{"La paronomasia en la literatura árabe y española" Estudio comparativo}

Abdel Aziz Fahd"

El estudio trata algunos puntos relacionados con la paronomasia: su origen; su aparición; y su desarrollo en la literatura árabe y espaňola. A la hora de plantear este trabajo, hemos tenido en cuenta tres aspectos, entre ellos la definición de la paronomasia en ambas literaturas:

1- Estudiando este fenómeno en la literatura española, hemos expuesto cómo los escritores y autores lo han tratado en épocas sucesivas: empezando por Aristoteles, pasando por los escritores del Siglo de Oro (los siglos XVI y XVII) y llegando hasta los escritores actuales, además de los testimonios que se pueden encontrar tanto en la antigua como en la moderna poesía española.

2- Del mismo modo, hemos señalado los puntos de vista de escritores y críticos árabes como los de Abdel Kaher Al-Guergany.

Por otra parte, nos sostenemos a algunos puntos de vista árabes que ven que la paronomasia es un fenómeno puramente árabe tanto en su origen como en su división. Esta perspectiva fue apoyada por bastantes muestras y testimonios tomadas del Noble Corán y de la litratura árabe. Además hemos planteado la recíproca influencia entre ambas literaturas: árabe y española.

Al final, concluyemos en que la paronomasia es un fenómeno occidental por el cual fueron influidos los árabes taduciendo algunas obras de la literalura griega que son de mayor interés, escritas durante la época del Califato Abasída como por ejemplo "las obras de Aristoteles".

Facultad de Al-Alsun. Universidad de Minia 


\author{
Abstract \\ Comparative Study: Ilomonyms in Both \\ the Arabic and in Spanish Literature.
}

Abdel Aziz Fahad

The research discusses some important points, which shed some light upon homonymy as its origin, its appearance and its development in both Arabic and Spanish literature. In c onducting this research, we take into a ccount s ome factors, which include the definition of homonym in both literatures.

Firstly: Through our study of homonymy in Spanish literature we shoed how the writers used homonymy in consecutive ages starting from Aristotle passing through the writers en the golden age of spanish literature (sixteenth and seventeenth centuries) and ending with the views of the contemporary writers, quotations from the old and modern Spanish literature.

Secondly: On one hand, we refered to the view of Arab writers and critics on homonymys, including Abd El Kahir El Gergany is one of them on the other hand, we mentioned the views of some Arabic critics who regarded homonymy as a pure Arabic phenomenon in its origin and in its division. The critics who were with this view have given us the sufficient evidence to support their opinion; we took all our proofs from the Holly Quraan and the literature mutual influence.

In this research, we dealt with the inter communication between the Arabic and Spanish literature.Finally, we can say that homonymy is a western phenomenon, and that the Arabs were influenced by this kind through translating some of the important works in the old great literature into Arabic during the Abbaside Caliphate, such works as Aristotle's.

Faculty of Al-Alsun. Minia University 


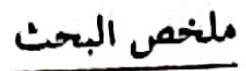

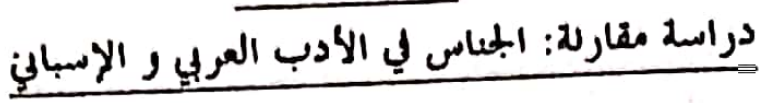

\section{عبد العزيز لهلد}




منها النعريف بابلناس في كلا الأدين:

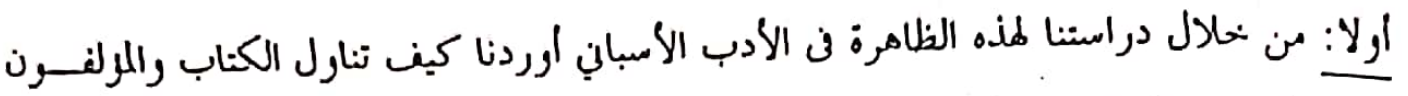

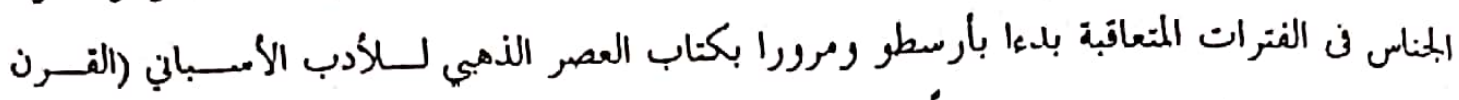

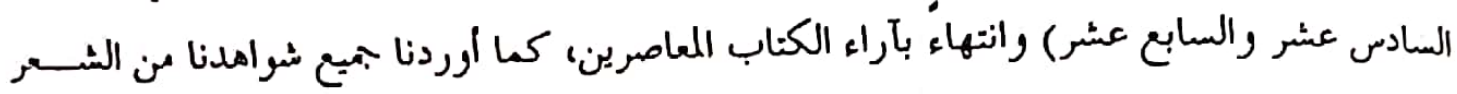
الأسباني القدى رالمديث على حلد سواء.

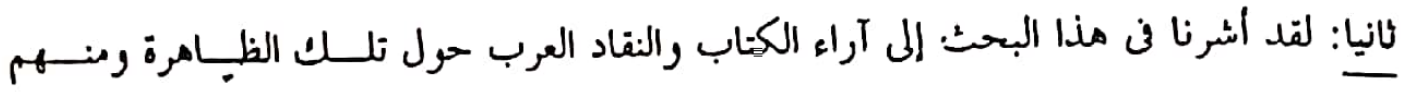



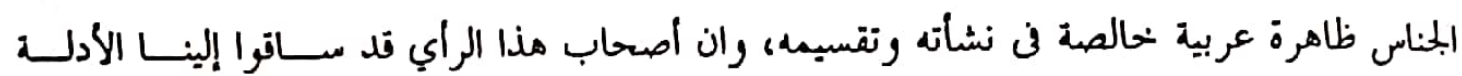
والبراهين الكافية لندعيم رائيهم، أخذنا جميع سواهدنا من القران الكريع والأدب العربي. نعرضنا فن البحث إلى عملية التأئير والتأثر بين كلا الأدبين العربي و الأسباني ور فن النهاية استطعنا


الأعمال الهامة من الأدب اليوناني القدم إلى اللغة العربية أثناء الحلافة العباسية ونذكر منها على مبيل المئل رليس الحصر "أعمال أرسطو". 